\title{
Analysis of Seedling Subsidy Policy and Cocoa Production in South-West Nigeria
}

\author{
Alamu, Salawu Abideen \\ Nigerian Institute of Social and Economic Research (NISER), \\ PMB 5, UI Post Office, Ibadan-Nigeria
}

\section{Doi:10.5901/jesr.2013.v3n4p59}

\begin{abstract}
The study analysis seedling subsidy policy and cocoa production in south-west Nigeria. Data were collected with questionnaires and interviews. Purposive sampling technique was used in the selection of Key Informants on cocoa production. Descriptive statistics and content analytical techniques were used for analysing the collected data. Findings showed that 79\%, 95\% and 96\% of local government areas in Oyo, Ondo and Osun States respectively are producing cocoa. Again, both Ondo and Oyo states have been supplying more than one million seedlings while Osun has been supplying 800,000 seedlings to their farmers every year since the commencement of seedling subsidy policy. The unit cost of the seedlings was between N10 and N20 in Ondo and Osun states respectively due to $50 \%$ subsidy while Oyo state was supplying the seedlings at $100 \%$ subsidy to the farmers. Ondo state produced the highest quantity of cocoa in 2005, 2006, 2009 and 2011 while Osun recorded highest production figure in 2007 and 2008. Inadequate funding, delay in release of funds and dearth of manpower are the major challenges to its implementation. The study recommends adequate and timely release of funds for seedling production and provision of $100 \%$ subsidy to enhance cocoa production in the country.
\end{abstract}

Key Words: Seedling subsidy, cocoa transformation, Nigeria.

\section{Introduction}

\section{1 Background}

Cocoa (Theobroma cacao) is a major economic tree crop in Nigeria because it provides jobs and income to the farmers, raw materials for the industry and foreign exchange for the country. Between 1950 and 1960, cocoa was the highest source of foreign exchange in the country (Oyedele, 2007). The discovery of oil in 1970, coupled with other socio-economic factors led to the relegation of cocoa to the second position in terms of foreign exchange earnings for the country. Since then, oil sector is the pivot of Nigerian economy with attendant poverty, unemployment and weak industrial base. Economic diversification is a panacea to the socio-economic problems in Nigeria. In order to diversify the Nigerian economy, the Federal Government of Nigeria (FGN) decided to rejuvenate cocoa industry with emphasis on increased production among other things. As a result, some interventions were introduced into cocoa industry with the aim of meeting the needs of the expanding industrial sector, increasing foreign exchange, enhancing job creation and farmers' income (FGN, 2006).

One of the government interventions into cocoa industry was the supply of improved seedlings at zero cost (subsidy) to the farmers. This aims at increasing the accessibility of the cocoa farmers to large quantity of cocoa seedlings to enhance their production capacity. The subsidy on improved seedlings was based on the fact that supply of adequate quantity of improved 
seedlings constitutes as a catalyst for agricultural development, foundation for crop production and productivity and realisation of agricultural transformation agenda in the country.

The focus of the subsidy is to rehabilitate the old cocoa plantations and establishment of new farms with improved seedlings to enhance increase in cocoa production in the country. This study analyses the provision of subsidy and its effects on cocoa production in the selected states.

\subsection{Problem Statement}

Cocoa used to be the highest source of foreign exchange earning in Nigeria before the oil boom of the 70s. Since then, crude oil has remained the highest source of foreign exchange earnings while cocoa, a versatile, renewable and sustainable source of revenue is yet to reclaim its lost glory. Again, the present Nigerian cocoa production figure which stood at 242, 000 metric tonnes is below the target of 320, 000 metric tonnes. The inability of Nigerian cocoa production figure to meet this target shows that the country is losing the monetary value expected from foreign exchange going by the present US\$2, 581.6 per tonne of the commodity. This shows that foreign exchange earning potential of cocoa has not been optimally utilised in Nigeria.

Also, cocoa production in Nigeria is retarded by declining productivity of the existing old cocoa trees. For example, Fasina et al, 2001 and CRIN, 2003 showed that most of the cocoa trees in the country have almost attained 30 years of age with diminishing production trend. These old trees coupled with their susceptibility to pest attack are responsible for decline in the quality and quantity of cocoa production in the country.

Cocoa production in Nigeria is undertaken mostly by poor, small scale and low technical capability farmers. These farmers therefore face difficulties in setting up of new cocoa farms and rehabilitation of old ones.

\subsection{Research Question}

The research questions addressed by this study were:

$>$ What is the level of subsidy provided for the farmers in the selected states?

$>$ How has the subsidy policy enhanced cocoa production in the selected states?

$>$ What are the problems in the implementation of the policy in the selected states?

\subsection{Research Objective}

The broad objective of the study was to analyse the seedling subsidy policy and cocoa production in the selected area. The specific objectives of the study were to:

$>$ Examine the level of subsidy provided in the selected states

$>$ Assess the effect of subsidy on the quantity of cocoa produced in the selected area;

$>$ Identify the constraints associated with implementation of the policy; and

$>$ Proffer measures for enhancing the achievement of the policy goals and objectives.

\subsection{Justification and Rationale for the Study}

The major justification for this study is that no study has assessed the government subsidy policy on the supply of cocoa seedlings to the farmers ever since its commencement. This study therefore became necessary in order to provide evidence that could guide policy direction towards improving its implementation.

The study aimed at contributing towards achieving increase in the production of cocoa in Nigeria by enhancing accessibility of cocoa farmers to improved varieties of cocoa seedlings. For example, Oladosu and Sanusi (2004) opined that cocoa farming, processing and marketing provide employment for about $40 \%$ of inhabitants in cocoa producing zones in Nigeria. Thus, seedling 
subsidy is expected to enhance the production of cocoa in the country with the objective of alleviating unemployment and improve the economic status of various actors in the cocoa industry. In addition, Ndubuto et al (2010) opined that Nigeria has comparative advantage in the production and exportation of cocoa, thus accessibility of farmers to adequate supply of cocoa seedlings at zero cost is expected to raise cocoa production in Nigeria and make the country the leading producer of in the world.

\section{Literature Review}

\subsection{Economic Importance of Cocoa in Nigeria}

Cocoa is one of the major cash crops with significant impact on the contribution of agricultural sector to the Nigerian economy. The vast contributions of cocoa to the nation's economic development have been reported by many authors (Abang 1984 and Folayan et al, 2006). Cocoa has made significant contributions in terms of total production, foreign exchange earning capacity and income generation to Nigerian economy since its introduction into the country. In the early 40 's, the cocoa industries contributed (on the average) $21.50 \%$ of all foreign exchange earned by Nigeria in the world market. In terms of foreign exchange earnings, no single agricultural export commodity has earned more than cocoa for Nigeria. With respect to employment generation, the cocoa sub-sector provides both direct and indirect employment to the producers, processors, retailers and other actors in cocoa industry. In addition, it is an important source of raw materials, as well as source of revenue to the governments of cocoa producing states in the country.

\subsection{Cocoa Production and Agricultural Development Programmes in Nigeria}

The oil boom of the 70s triggered fundamental changes in Nigerian economy most especially in agricultural sector. The monolithic oil economy led to reduction in the competitiveness of the nation's agriculture. In order to revive agriculture, various policies and programmes were put in place during national plan periods in Nigeria to revitalise the production of tree and food crops. For example, between 1962 and 1968 agricultural plan periods, the development of tree crops like cocoa, oil palm and rubber, gulped $45 \%$ of planned capital allocation. Efforts were made during this period to rehabilitate cocoa plantations through gradual replacement of old trees with improved stock through subsidy payment. In addition, farm settlement schemes were also set up to address lingering problems associated with land tenure, access to sources of capital and new technology. Government also provided infrastructural facilities like road and furnished houses. The scheme however failed to achieve its goal (Titilola, 1997) due to absence of sustainable government efforts.

Again, the 1970 and 1974, the national agricultural policy also favoured the production of export crops. Both the federal and state governments were guided by the objectives of rehabilitating cocoa and oil palm plantations by replacing the old trees with high yielding and improved varieties. Increased production of tree crops was also encouraged by subsidising the prices of inputs and provision of extension services to small scale farmers. Government also embarked on expansion in the production of export crops for foreign exchange earnings; creation of rural employment opportunities and establishment of appropriate institutional and administrative apparatus to facilitate agricultural development in the country. Other component of the government agricultural policy initiatives in the 70s was the launching of Agricultural Credit Guaranteed Scheme (ACGS) when the Nigerian Agricultural and Cooperative Bank (NACB) was established in 1973 to provide credit facilities to small scale farmers in the country. This action represented a very conspicuous contribution of FGN to agricultural development.

Provision of price and tax incentives was the major policy thrust of the government during the third National Plan period (1975-1980). The agricultural promotional activities included the use of 
fiscal measures and tax relief to induce private companies into agricultural production, subsidising essential inputs and provision of extension services. During this period, the World Bank assisted small scale tree crop farmers to engage in massive replanting of old trees with improved seedlings.

Decline in export of cocoa and other agricultural raw materials led to the formulation of agricultural policy of 1988. One of the objectives of the policy was to accelerate the production of cash crops in order to expand the quantity and value. The policy focus then was to promote cocoa research, supply of improved inputs and increase in size of farm under cultivation.

The return of civilian administration in 1999 ushered in a good fortune for cocoa production in Nigeria due to the introduction of new policy and programme to cocoa industry in the country. The FGN established the National Cocoa Development Committee (NCDC) in 2000 and domiciled it in the Federal Ministry of Agriculture and Rural Development (FMA\&RD). This Committee was charged with the responsibility of developing a blue print for reviving the nation's cocoa industry with a special focus on its rehabilitation. The rehabilitation programme aims at increasing the quantity and quality of cocoa produced in Nigeria. In order to sustain and improve on these performances, the President of Nigeria launched a special programme tagged cocoa re-birth in 2005 . The policy thrust of the programme was to promote the production of cocoa to meet the needs of an expanding industrial sector and export market. The programme also aimed at creating jobs and wealth in order to enhance farmers' income and reduce poverty in the country (FGN, 2006). Some of the targets of the policy are to improve the farmers' income and increase cocoa production from 170, 000 Metric tonnes to 320,000 metric tonnes per annum in short term and 600,000 metric tonnes per annum (pa) in long term. Some of the federal government strategies for achieving the objectives include:

- Supply of cocoa seedlings to the farmers at subsidized rate for planting new and old cocoa farms;

- Intensification of applied research by strengthening the Agricultural Research Council of Nigeria and other agricultural research institutions.

- Sensitization and training of cocoa farmers to bring out the best in varieties planted, cocoa tree management, good quality formation and soil management;

- Rehabilitation and regeneration of old moribund cocoa trees/ plantations to arrest dwindling harvests/output;

- Youth attraction into cocoa farming to ensure adequate replacement of the current ageing generation of farmers.

The provision of subsidy in form of fertilizers, seeds and seedlings is fundamental to agricultural development across the globe. Agricultural input subsidy has enhanced the use of fertilizer in many countries across the globe. For example, fertilizer subsidy accounts for the use of $100 \mathrm{~kg}$ per hectare of fertilizer in South Asia and $73 \mathrm{~kg}$ per hectare of the same commodity in Latin America while bottleneck in the provision of fertilizer subsidy accounts for the use of $9 \mathrm{~kg}$ per hectare in Africa (Crawford et al, 2006).

Across the globe, both Universal and Smart approaches are used in the implementation of subsidy programmes in agriculture. The Universal approach is a government controlled input marketing system in which farmers are supplied with agricultural input at controlled or subsidised price. The approach though contributes to increase in agricultural production, also allows for better connected farmers and relatively well-off farmers to benefit and advance in agricultural productivity. The approach depends on continued government support, while it is also prone to inefficiency arising from high administrative cost, government monopolies and political manipulation (Banful, 2010). The Smart approach focuses on targeting specific farmers and provision of market-based solution with a view to addressing the shortcomings of universal subsidy implementation system (Minde et al, 2008; Tiba, 2009). 


\section{Methodology}

\subsection{The Study Area}

Three states in the Southwest Nigeria selected for the study were: Oyo, Osun and Ondo states. They were selected because they are major cocoa producing states in Nigeria. Since the information required for this study are obtainable from the government, the government Officials (Key Informants) in the Tree Crops Unit/ Cocoa Development Unit in the selected states provided the necessary data for the study. These Officials are responsible for the implementation of various programmes and policies on cocoa production.

\subsection{Types of Data}

Both quantitative and qualitative data were collected for the study. Data collected for the study included: background information about cocoa production in their respective states, the provision of seedling subsidy to the farmers, the commencement period of the subsidy, the characteristic and number of cocoa seedlings produced and distributed to the farmers since the inception of the programme, size of cocoa farm envisaged to plant, number of farmers that benefitted, level of fund provided for the service, adequacy of the fund provided and the level of available funds for the programme and challenges associated with the implementation of the policy.

\subsection{Sampling Size and Procedure}

The ministry of agriculture in each of the three states was contacted in the selection of key informants on cocoa production. One key Official was nominated as Key Informant to attend to the Principal Investigator for interview in each of the three states under consideration.

\subsection{Research Instrument}

Questionnaire and Interviews were the data collection instruments. They were used to obtained data from the Key Informants.

\subsection{Data Analysis}

Descriptive statistical tools like frequency counts and percentages were used for the quantitative data while content analytical technique was used for the qualitative data.

\section{Results and discussion}

\subsection{Background Information about Respondents}

Analysis of data on the study area showed that $79 \%$ (19 out of 24 ), 95\% (18 out of 19) and $97 \%$ (29 out of 30) of local government areas in Oyo, Ondo and Osun states respectively are producing cocoa. In addition, these states have Cocoa Development Unit/ Tree Crops Unit (CDU/TCU) that are collaborating with the National Cocoa Development Council (NCDC) on the implementation of the various government policies and programmes on cocoa.

An excerpt from the responses obtained through interviews conducted on the key informants on cocoa production in all the three states under review on the time of commencement of seedling subsidy and supply is as follows: 
"The provision of seedlings subsidy to cocoa farmers was already in place even before the commencement of the cocoa re-birth programme in the country. The launching of cocoa re-birth programme however, enhances the seedling subsidy because both the state and federal government are jointly implementing it in order to achieve agricultural transformation agenda in the country" (Production Manager, Ministry of Agriculture, Ondo State.

Table 4.1.1 shows the number of cocoa seedlings supplied to the farmers by the three states under review between 2005 (when cocoa rebirth programme was launched) and 2011. The Table shows that the three states under focus have supplied appreciable quantities of cocoa seedlings to the farmers in their respective states between 2005 and 2011. This gesture demonstrates the level of commitment by these states in seedling supply policy. The quantity of cocoa seedling supplied by Ondo state was the highest among the three states while Osun state has the least.

Table 4.1.1: Quantity of Cocoa Seedlings Supplied to Farmers in the Selected States

\begin{tabular}{|l|l|l|l|l|l|l|l|}
\hline \multirow{2}{*}{ State } & \multicolumn{7}{|c|}{ Years } \\
\cline { 2 - 8 } & $\mathbf{2 0 0 5}$ & $\mathbf{2 0 0 6}$ & $\mathbf{2 0 0 7}$ & $\mathbf{2 0 0 8}$ & $\mathbf{2 0 0 9}$ & $\mathbf{2 0 1 0}$ & $\mathbf{2 0 1 1}$ \\
\hline Oyo & 843,251 & $1,400,000$ & $1,500,000$ & $1,000,000$ & $1,000,000$ & $1,100,000$ & $\mathrm{Na}$ \\
\hline Osun & $\mathrm{Na}$ & 404,000 & $1,600,000$ & 600,000 & 900,000 & $1,300,000$ & 100,000 \\
\hline Ondo & $1,540,000$ & $3,040,000$ & $1,292,312$ & 908,126 & 906,993 & $1,192,503$ & $1,232,360$ \\
\hline
\end{tabular}

Source: Field Survey, 2012

The adequacy of the supply of the seedlings is essential for the cultivation of new areas and replanting of old trees envisaged by the farmers. Data collected from the three states show inadequate supply of seedlings to the farmers. An excerpt from the responses obtained through interviews conducted on the key informants on the inadequate supply of cocoa seedlings to the farmers is as follows:

There is inadequate cocoa seedling supply. This is a clog in the realisation of the objectives of cocoa re-birth and agricultural transformation agenda in the country. Government must address this problem without further delay"(Production Manager, Tree crops Unit, Ministry of Agriculture, Natural Resources and Rural Development, Oyo state).

The cost of production of seedlings in the three states under focus also varies. In Ondo state, the cost of a seedling was between N20 and N50 while the cost of a seedling in Osun and Oyo states was $\mathrm{N} 20$ and N12 respectively. This shows that the cost of production of cocoa seedlings is highest in Ondo state followed by Osun and Oyo in descending order.

One major objective of seedling subsidy policy in cocoa industry is to increase the size of new cocoa farms and replanting of old trees. The utilisation of the seedlings for expansion in the size of cocoa farms in the selected states is shown in Table 4.1.2. The Table shows that Oyo state recorded increase in size of new cocoa farms planted with the new seedlings between 2005 and 2008. The State however recorded decrease in the size of new area planted with hybrid seedlings between 2009 and 2010 but pick up again in 2011. In Ondo State, the size of cocoa farm planted with new seedlings was highest (2923) in 2006 but nose dived in between 2007 and 2010 before rising again to 1147 ha in 2011. 
Table 4.1.2: New Area Planted with Hybrid Seedlings

\begin{tabular}{|l|l|l|l|l|l|l|l|}
\hline \multirow{3}{*}{ State } & \multicolumn{7}{|c|}{ Years } \\
\cline { 2 - 8 } & $\mathbf{2 0 0 5}$ & $\mathbf{2 0 0 6}$ & $\mathbf{2 0 0 7}$ & $\mathbf{2 0 0 8}$ & $\mathbf{2 0 0 9}$ & $\mathbf{2 0 1 0}$ & $\mathbf{2 0 1 1}$ \\
\hline Oyo & 532 & 719 & 1275 & 1367 & 911 & 903 & 1296 \\
\hline Osun & & 2923 & 1240 & 873 & 884 & 872 & 1147 \\
\hline Ondo & 402 & 211 & 294 & 270 & 324 & 180 & 90 \\
\hline
\end{tabular}

Source: Field Survey, 2012.

Table 4.1.3 shows the size of cocoa farms in ha planted with hybrid seedlings in the study areas. Only Oyo State has data on this area. It is however, worrisome to note that both Osun and Ondo states have no data. This is a major gap in the monitoring of implementation of the effects of seedling subsidy policy on cocoa re-birth and agricultural transformation agenda in the country.

Table 4.1.3: Number of Old Trees Replanted in the Study Areas

\begin{tabular}{|l|l|l|l|l|l|l|l|}
\hline \multirow{2}{*}{ State } & \multicolumn{7}{|c|}{ Years } \\
\cline { 2 - 8 } & $\mathbf{2 0 0 5}$ & $\mathbf{2 0 0 6}$ & $\mathbf{2 0 0 7}$ & $\mathbf{2 0 0 8}$ & $\mathbf{2 0 0 9}$ & $\mathbf{2 0 1 0}$ & $\mathbf{2 0 1 1}$ \\
\hline Oyo & 25,124 & 24,824 & 24,156 & 23,196 & 23,030 & na & na \\
\hline Osun & $\mathrm{Na}$ & $\mathrm{na}$ & $\mathrm{Na}$ & $\mathrm{Na}$ & $\mathrm{na}$ & na & na \\
\hline Ondo & $\mathrm{Na}$ & $\mathrm{na}$ & $\mathrm{Na}$ & $\mathrm{Na}$ & na & na & na \\
\hline
\end{tabular}

Source: Field Survey, 2012

The provision of seedlings to cocoa farmers is a policy intervention which aims at enhancing farmers' access to adequate seedlings for their planting exercise. The fact that it is a subsidy shows that government will bear part or total cost of the production of the seedlings. Table 4.1.4 shows the level of subsidy provided by each of the states covered in this study on the supply of seedlings to cocoa farmers. The Table shows that while Oyo state government was supplying the seedlings to the farmers at 100 percent subsidy, both Ondo and Osun states were selling the seedlings to the farmers at 50 percent subsidy. This shows that the cost of a seedling in Ondo state is N20 while the cost of a cocoa seedling in Osun state is N10 as a result of the subsidy. The result of interview conducted on the key informants in Osun and Ondo states on seedling subsidy revealed that:

'Only seedlings produced through federal government funds are supplied to the farmers at 100 percent subsidy while those produced by the state government are sold at $50 \%$ subsidy to the farmers (Production Manager, Cocoa Development Unit, Ministry of Agriculture, Ondo State).

Table 4.1.4: Level of Subsidy on Cocoa Seedlings in the Study Area

\begin{tabular}{|l|l|l|l|l|l|l|l|l|}
\hline & \multicolumn{7}{|c|}{ Level of Subsidy (\%) } \\
\hline State & 2005 & 2006 & 2007 & 2008 & 2009 & 2010 & 2011 & 2012 \\
\hline Oyo & 100 & 100 & 100 & 100 & 100 & 100 & 100 & 100 \\
\hline Ondo & 50 & 100 & 50 & 50 & 50 & 50 & 50 & 50 \\
\hline Osun & 50 & 50 & 50 & 50 & 50 & 50 & 50 & 50 \\
\hline
\end{tabular}

Source: Field survey, 2012. 


\subsection{Effects of Seedling Subsidy Policy on Cocoa Production in the Selected Areas}

The major reason for the provision of subsidy on cocoa seedling is to boost cocoa production in the country through rehabilitation of old cocoa farms and establishment of new farms. Table 4.2.1 shows the yield in metric tonnes of cocoa produced in the selected states. According to the Table, Ondo state has the highest production figure for the years 2005, 2006, 2009, 2010 and 2011 while state of Osun has the highest production figures in 2007 and 2008 and also had the second highest production figure for the years 2005, 2006, 2009 and 2010. The Table further shows that Oyo is recording a marginal increase in yearly production of cocoa between 2005 and 2011.

The Table further shows that the increasing rate of cocoa production is marginal most especially in both Oyo and Osun states. This implies that the seedling subsidy policy of the cocoa rebirth programme has not significantly contributed to cocoa production in the selected states. On this issue, one of the key informants responded as follows:

"It is a matter of time. Seedling subsidy policy will obviously contribute to increase in the production of cocoa because the seedlings being supplied to the farmers are hybrid with high yielding capacity, early maturing (three years maturity period), easy to harvest (short) and higher resistance to diseases among other characteristics" ( Deputy production Manager, Cocoa development Unit, Osun state Ministry of Agriculture and Poverty Alleviation)

Table 4.2.1: Yield (metric tonnes) of Cocoa in the Study Area

\begin{tabular}{|l|l|l|l|l|l|l|l|}
\hline \multirow{2}{*}{ State } & \multicolumn{9}{|c|}{ Years } \\
\cline { 2 - 8 } & $\mathbf{2 0 0 5}$ & $\mathbf{2 0 0 6}$ & $\mathbf{2 0 0 7}$ & $\mathbf{2 0 0 8}$ & $\mathbf{2 0 0 9}$ & $\mathbf{2 0 1 0}$ & $\mathbf{2 0 1 1}$ \\
\hline Oyo & 36,756 & 37,904 & 37,982 & 38,231 & 38,463 & Na & na \\
\hline Osun & 56,960 & 52,160 & 58,000 & 65,120 & 62,100 & 60,750 & 62,250 \\
\hline Ondo & 57,076 & 61,835 & 45,004 & 60,039 & 76,399 & 65,224 & 76,558 \\
\hline
\end{tabular}

Source: Field survey, 2012

\subsection{Challenges and Constraints in the Supply of Cocoa Seedlings}

The results of analysis of data collected from the Key Informants revealed the challenges confronting the production and distribution of cocoa seedlings to farmers in the selected states. One of the state officials reported that:

"Inadequate fund, delay in release of funds, dearth of manpower and infrastructures like water, health and good road network are the major challenges confronting them in the production and supply of cocoa seedlings in the three states under consideration". Some temporary staff (Casuals) are usually engaged in order to have adequate manpower to achieve the production of required quantity of seedlings. (Production Manager, Tree Crops Unit, Ministry of Agriculture, Oyo State)

\subsection{Policy Recommendations}

The accessibility of the farmers to adequate and timely supply of hybrid cocoa seedlings is a strategic way of realising the cocoa transformation agenda of the FGN. The accessibility of the farmers to adequate and timely supply of hybrid cocoa seedlings will enhance the rehabilitation of 
old plantations and cultivate new ones. This will enable the farmers to obtain a higher return on their investment in cocoa production and a better livelihood.

In order to ensure adequate supply of hybrid seedlings to the farmers, the following suggestions are provided.

\section{Provision of Adequate and Timely release of Funds:}

Government at state and federal levels should ensure timely release of adequate fund for the production of hybrid cocoa seedlings in the country. The Federal Government in particular needs to provide more financial assistance to the cocoa producing states on the production of the seedlings.

\section{Collection of Accurate and Reliable Data on Cocoa Farmers:}

Government should as a matter of priority, have adequate and reliable statistics about the number of cocoa farmers, their farm size and their needs. This will assist the government in the implementation of their various policies and programmes on cocoa re-birth in the country.

\section{Re-Appraisal of Seedling Subsidy Policy:}

The FGN needs to look into the level of subsidy provided for the cocoa farmers on seedlings in all the cocoa producing states. In order to allow farmers have more access to hybrid seedlings, it is suggested that government should provide seedlings to the farmers at $100 \%$ subsidy. This will remove the cost of procurement of seedlings from other associated costs in the rehabilitation of old plantations and cultivation of new ones.

\section{Placement of Restriction on Farmers and Private Seedling Producers:}

In order to achieve the objectives of the production and supply of hybrid cocoa seedlings in the country, farmers should be discouraged from procuring their seedlings from the private cocoa seedlings producers. This is very essential for averting the danger of procuring adulterated seedlings with lower yield, susceptible to pest attack and late maturing. In addition, private seedling producers should no longer be allowed to produce cocoa seedlings for the farmers in the country. This will put an end to the production of adulterated seedlings and allow farmers to purchase genuine seedlings from government approved agencies and institutions in the country.

\section{References}

Abang, S.O. (1984). Stabilisation Policy: An Economic Analysis and Evaluation of its Implication for Nigerian Cocoa farmers. Ph.D Thesis, Oklahoma State University, Stillwater, USA.

Banful, A; and Branoah (2010). Old problems in the new solutions? IFPRI Discussion Paper 01002, Washington D.C., IFPRI.

Crawford, E, Jayne, T.S. and Valerie A. K. (2006). Alternative Approaches for Promoting Fertilizer Use in Africa. Agriculture and Rural Development Discussion Paper 22, Washington D.C.

Cocoa Research Institute of Nigeria (CRIN) (2003). Bulletin of Cocoa Research Institution of Nigeria CRIN, Ibadan, Vol. 12 (2003).

Fasina, A.B.; Badaru, K and Aikpokpodion, P.O. (2001). Development of the Nigerian cocoa industry: current issues and challenges for research and production. Proc. $13^{\text {th }}$ Int. Cocoa Res. Conf. 2001, pp. 1367 1373.

FGN (2006). Nigeria: National Report, International Conference on Agrarian Reform and Rural Development, Porto Alegre, 7-10 March 2006.

Folayan, J. A., Daramola, G. A. and Oguntade, A. E., (2006): "Structure and performance evaluation of cocoa marketing institutions in South-Western Nigeria: An economic analysis". J ournal of Food, Agriculture and Environment 4 (2): 123-128.

Minde, I, J ayne, T.S, Crawford, E; Ariga, J and Govereh, J (2008). Promoting Fertilizer Use in Africa: Current Issues and Empirical Evidence from Malawi, Zambia, and Kenya. Paper prepared for the Regional Strategic Agricultural Knowledge Support System (ReSAKSS) for Southern Africa, Working Paper No.13, Food Security Group, Michigan State University 
Ndubuto, N.I.; Agu, N; Nwan, J and Imonikhe, G. (2010). Competitiveness and Determinants of Cocoa Export from Nigeria.

Oladosu, J.O. and Sanusi, W.A. ( 2004). Communication Effectiveness between Cocoa Research Institute of Nigeria (CRIN) and Cocoa Farmers in Cocoa Producing Areas of Oyo State, Nigeria. J ournal of Rural Research and Information, 1: 77-86.

Oyedele, J.O. (2007). Enhancing the Sustainability of Cocoa Growing in Nigeria. A Paper Presented at the Cocoa Roundtable on a Sustainable World Cocoa Economy, Accra, Ghana, 3-6 October.

Tiba, Z. (2009). The role of input subsidies: Operational guidelines on implementation. Policies for Good Economic Management of Food Price Swings in African Countries. Rome, FAO Trade and Markets Division.

Titilola, S.O. (1997). An Econometric Model of Nigeria's Agricultural Sector with Emphasis on the Future of Cocoa in the Nigerian Economy (1970-1990). NISER Monograph Series N0. 12. 